\title{
PENGARUH PELATIHAN, MOTIVASI, DAN LINGKUNGAN \\ KERJA TERHADAP KINERJA KARYAWAN KEMENTERIAN PERHUBUNGAN DI UNIT KERJA DIREKTORAT JENDERAL PERHUBUNGAN UDARA PADA KANTOR OTORITAS BANDAR UDARA WILAYAH VII BALIKPAPAN
}

\author{
PUDJIATI \\ Jurusan Manajemen Fakultas Ekonomi Universitas Balikpapan \\ Pudjiati1804@gmail.com
}

\begin{abstract}
ABSTRAKS
Tujuan penelitian adalah untuk mengetahui pengaruh variabel pelatihan, motivasi kerja, dan lingkungan kerja terhadap kinerja Karyawan Kementerian Perhubungan di Unit Kerja Direktorat Jenderal Perhubungan Udara Pada Kantor Otoritas Bandar Udara Wilayah VII Balikpapan.

Hasil penelitian adalah persamaan regresi linear berganda :

$Y=0,534+0,292 X_{1}+0,348 X_{2}+0,268 X_{3}$

Hasil analisis pengujian secara simultan dengan menggunakan analisis Fisher test yaitu diperoleh nilai F-hitung sebesar sedangkan $\mathrm{F}$ tabel dengan derajat keyakinan $95 \%(\alpha=0,05)$ maka diketahui F-hitung $=82,937>$ F-tabel $=2,83$ pada sig sebesar $0,000<0,05$ dan diperoleh hasil koefisien korelasi $(\mathrm{R})=0,927$ berarti terdapat adanya hubungan yang kuat antara variabel Variabel Pelatihan $\left(\mathrm{X}_{1}\right)$, Motivasi kerja $\left(\mathrm{X}_{2}\right)$, dan Lingkungan kerja $\left(\mathrm{X}_{3}\right)$ terhadap Kinerja Karyawan (Y) Kementerian Perhubungan di Unit Kerja Direktorat Jenderal Perhubungan Udara Pada Kantor Otoritas Bandar Udara Wilayah VII Balikpapan dengan nilai koefisien korelasi $(\mathrm{R})=0,927$ yang mendekati angka 1 . Nilai koefisien determinasi $\left(\mathrm{R}^{2}\right)=0,861$ nilai ini menunjukkan bahwa pengaruh secara bersamasama Variabel Variabel Pelatihan $\left(X_{1}\right)$, Motivasi kerja $\left(X_{2}\right)$, dan Lingkungan kerja (X3) terhadap Kinerja Karyawan (Y) Kementerian Perhubungan di Unit Kerja Direktorat Jenderal Perhubungan Udara Pada Kantor Otoritas Bandar Udara Wilayah VII Balikpapan sebesar 85,9\% dan sisanya sebesar 14,1\% merupakan kontribusi variabel lain yang tidak masuk analisis penelitian ini.
\end{abstract}

Kata Kunci : Pelatihan, Motivasi kerja, dan Lingkungan kerja ,Kinerja Karyawan.

\section{ABSTRACT}

The purpose of this research is to know the effect of training variables, work motivation, and work environment on the performance of the employees of the Ministry of Transportation at the Work Unit of the Directorate General of Civil Aviation at the Office of VII Balikpapan Airport Authority.

The result of the research is multiple linear regression equation:

$Y=0,534+0,292 X 1+0,348 X 2+0,268 X 3$

The result of simultaneous test analysis by using Fisher test analysis is obtained $F$-count value as big as whereas $F$ table with degree of confidence 95\% $(\alpha=$ 
$0,05)$ hence known F-count $=82,937>F$-table $=2,83$ at sig equal $0.000<0,05$ and the result of correlation coefficient $(R)=0,927$ means there is a strong correlation between variable of Training Variable (X1), Work Motivation (X2), and Work Environment (X3) to Employee Performance (Y) Ministry of Transport at Work Unit of Directorate General of Civil Aviation at the Office of VII Balikpapan Airport Authority with the value of correlation coefficient $(R)=0.927$ approaching the number 1 . The coefficient of determination $\left(R^{2}\right)=0.861$ This value indicates that the influence of Variable Variable Training (X1 ), Working Motivation (X2), and Work Environment (X3) on Employee Performance (Y) Ministry of Transportation at Work Unit of Directorate General of Civil Aviation at the Office of Airport Authority Wi layak VII Balikpapan amounted to 85.9\% and the rest of $14.1 \%$ is the contribution of other variables that do not enter the analysis of this study.

Keywords: Training, Work Motivation, and Work Environment, Employee Performance.

\section{PENDAHULUAN}

Transportasi antar kota yang sedang marak saat ini adalah transportasi udara, karena transportasi udara merupakan modal transportasi yang efektif, efisien, cepat, selamat, dan nyaman, GintaPedhiena (2011:21). Transportasi udara merupakan salah satu transportasi yang paling digemari oleh masyarakat, yakni transportasi udara niaga. Hal ini karena banyak digunakan untuk kepentingan bisnis, kepentingan pariwisata dan berbagai urusan lainnya, sehingga mengalami perkembangan yang sangat pesat. Perkembangan pesat transportasi udara dapat dilihat dari semakin banyaknya maskapai penerbangan seperti Lion Air, Garuda dan lainnya.

Pegawai merupakan asset utama organisasi dan mempunyai peran yang strategis didalam organisasi yaitu sebagai pemikir, perencana, dan pengendali aktivitas organisasi. Demi tercapainya tujuan organisasi, karyawan memerlukan motivasi untuk bekerja lebih rajin. Melihat pentingnya karyawan dalam organisasi, maka karyawan diperlukan perhatian lebih serius terhadap tugas yang dikerjakan sehingga tujuan organisasi tercapai. Dengan motivasi kerja yang tinggi, karyawan akan bekerja lebih giat didalam melaksanakan pekerjaannya. Sebaliknya dengan motivasi kerja yang rendah karyawan tidak mempunyai semangat bekerja, mudah menyerah, dan kesulitan dalam menyelesaikan pekerjaannya.

Selain faktor motivasi kerja, lingkungan kerja tempat karyawan tersebut bekerja juga tidak kalah pentingnya didalam meningkatkan kinerja karyawan. Dimana Lingkungan Kerja adalah kondisi-kondisi material dan psikologis yang ada dalam organisasi. Maka dari itu organisasi harus menyediakan lingkungan kerja yang memadai seperti lingkungan fisik (tata ruang kantor yang nyaman, lingkungan yang bersih, pertukaran udara yang baik, warna, penerangan yang cukup maupun musik yang merdu), serta lingkungan non fisik (suasana kerja karyawan, kesejahteraan karyawan, hubungan antar sesama karyawan, hubungan antar karyawan dengan pimpinan, serta tempat ibadah). Lingkungan kerja yang 
baik dapat mendukung pelaksanaan kerja sehingga karyawan memiliki semangat bekerja dan meningkatkan kinerja karyawan.

Untuk menciptakan kinerja yang tinggi, dibutuhkan adanya peningkatan kerja yang optimal dan mampu mendayagunakan potensi Sumber Daya Manusia yang dimiliki oleh karyawan guna menciptakan tujuan organisasi, sehingga akan memberikan kontribusi positif bagi perkembangan organisasi. Selain itu, organisasi perlu memperhatiksn berbagai faktor yang dapat mempengaruhi motivasi karyawan, dalam hal ini diperlukan adanya peran organisasi dalam meningkatkan motivasi dan menciptakan lingkungan kerja yang kondusif guna mendorong terciptanya sikap dan tindakan yang profesional dalam menyelesaikan pekerjaan sesuai dengan bidang dan tanggung jawab masing-masing.

Sejalan dengan uraian di atas, Karyawan Kementerian Perhubungan di Unit Kerja Direktorat Jenderal Perhubungan Udara Pada Kantor Otoritas Bandar Udara Wilayah VII Balikpapan yang bergerak di bidang penerbangan harus terus menerus dan berkesinambungan dalam melaksanakan pelatihan dan memotivasi karyawan agar keterampilan, kecakapan, dan sikap karyawan meningkat sehingga setiap pekerjaan akan lebih mudah diselesaikan tepat waktu dan tepat sasaran yang pada akhirnya akan meningkatkan produktivitas dan profitabilitas perusahaan. Tinggi rendahnya pengetahuan, keterampilan dan motivasi kerja karyawan Karyawan Kementerian Perhubungan di Unit Kerja Direktorat Jenderal Perhubungan Udara Pada Kantor Otoritas Bandar Udara Wilayah VII Balikpapan dalam meningkatkan kinerjanya dapat mempengaruhi kemampuan perusahaan dalam meningkatkan produktivitasnya.

Berdasarkan permasalahan di atas, maka tujuan penelitian ini adalah:

Untuk mengetahui variabel pelatihan, motivasi kerja, dan lingkungan kerja secara bersama-sama dan juga secara parsial berpengaruh terhadap kinerja Karyawan Kementerian Perhubungan di Unit Kerja Direktorat Jenderal Perhubungan Udara Pada Kantor Otoritas Bandar Udara Wilayah VII Balikpapan, dan juga untuk mengetahui diantara variabel pelatihan, motivasi kerja, dan lingkungan kerja yang berpengaruh dominan terhadap kinerja Karyawan Kementerian Perhubungan di Unit Kerja Direktorat Jenderal Perhubungan Udara Pada Kantor Otoritas Bandar Udara Wilayah VII Balikpapan.

\section{LANDASAN TEORI, KAJIAN EMPIRIS DAN PENGEMBANGAN HIPOTESIS}

\section{LANDASAN TEORI}

\section{Pelatihan}

Pelatihan adalah suatu kegiatan untuk memperbaiki kemampuan kerja seseorang dalam kaitannya dengan aktivitas ekonomi. Pelatihan membantu karyawan dalam memahami suatu pengetahuan praktis dan penerapannya, guna meningkatkan keterampilan, kecakapan, dan sikap yang diperlukan organisasi dalam usaha mencapai.

Menurut Siagian (2008: 175) defenisi pelatihan adalah: Proses belajar mengajar dengan menggunakan teknik dan metoda tertentu secara konsepsional dapat dikatakan bahwa latihan dimaksudkan untuk meningkatkan keterampilan 
dan kemampuan kerja seseorang atau sekelompok orang. Biasanya yang sudah bekerja pada suatu organisasi yang efisiensi, efektivitas dan produktivitas kerjanya dirasakan perlu untuk dapat ditingkatkan secara terarah dan pragmatik.

Pelaksanaan pelatihan dimaksudkan untuk mendapatkan tenaga kerja yang memiliki pengetahuan, keterampilan yang baik, kemampuan dan sikap yang baik untuk mengisi jabatan pekerjaan yang tersedia dengan produktivitas kerja yang tinggi, yang mampu menghasilkan hasil kerja yang baik. Kebutuhan untuk setiap pekerja sangat beragam, untuk itu pelatihan perlu dipersiapkan dan dilaksanakan sesuai dengan bidang pekerjaannya, dengan demikian pekerjaan yang dihadapi akan dapat dikerjakan dengan lancar sesuai dengan prosedur yang benar.

Pelatihan marupakan kegiatan untuk meningkatkan pengetahuan, kemampuan, keterampilan dan perubahan sikap individu dalam perusahaan agar dalam kelaksanakan tugas yang diembannya menjadi lebih baik lagi.

Faktor-faktor yang menunjang kearah keberhasilan pelatihan menurut Veithzal Rivai (2004:240) antara lain:
a. Materi
b. Metode
c. Prinsip pembelajaran
d. Ketetapan dan kesesuaian fasilitas
e. Kemampuan peserta pelatihan.

\section{Motivasi}

Secara sederhana, dalam teori ini, motivasi merupakan interaksi antara harapan setelah dikurangi prestasi, dengan kontribusi penilaian yang dikaitkan dengan prestasi dikurangi hasil. Karena kebutuhan di atas merupakan generalisasi karena kenyataannya kebutuhan orang tidak sama, maka dikenai The Expectacy Model yang menyatakan. "Motivasi adalah fungsi dari berapa banyak yang diinginkan dan berapa besar kemungkinan pencapaiannya".

Dari teori di atas dapat ditarik kesimpulan bahwa untuk meningkatkan motivasi, maka seorang manajer harus (Gomes, 2003):

1. Mengakui bahwa setiap pegawai memiliki kebutuhan yang berbeda dan preferensi yang berbeda pula. Tidak ada dua orang yang benar-benar memiliki kebutuhan yang sama.

2. Mencoba memahami kebutuhan utama seorang pegawai. Memahami apa yang dibutuhkan apalagi kebutuhan utama pegawai, merupakan perilaku atasan yang dicintai bawahan.

3. Membantu seorang pegawai menentukan upaya mencapai kebutuhannya melalui prestasi. Hal ini tidak sulit jika dilakukan dengan ketulusan, bukan pamrih.

Menurut Gomes (2003:68) manfaat motivasi yang utama adalah menciptakan gairah kerja, sehingga produktivitas kerja meningkat. Sementara itu, manfaat yang diperoleh karena bekerja dengan orang-orang yang termotivasi adalah pekerjaan dapat diselesaikan dengan tepat. Artinya pekerjaan diselesaikan sesuai standar yang benar dan dalam skala waktu yang sudah ditentukan, serta orang senang melakukan pekerjaannya. Sesuatu yang dikerjakan karena ada motivasi yang mendorongnya akan membuat orang senang mengerjakannya. 
Orang pun akan merasa dihargai/diakui, hal ini terjadi karena pekerjaannya itu betul-betul berharga bagi orang yang termotivasi, schingga orang tersebut akan bekerja keras. Hal ini dimaklumi karena dorongan yang begitu tinggi menghasilkan sesuai target yang mereka tetapkan. Kinerjanya akan dipantau oleh individu yang bersangkutan dan tidak akan membutuhkan terlalu banyak pengawasan serta semangat juangnya akan tinggi.

Motivasi merupakan suatu dorongan kebutuhan dalam diri pegawai yang perlu dipenuhi agar pegawai tersebut dapat menyesuaikan diri terhadap lingkungannya.

Menurut Gomes (2002) Faktor pemuas yang disebut juga motivator yang merupakan faktor pendorong seseorang untuk berprestasi yang bersumber dari dalam diri seseorang tersebut (kondisi intrinsik) antara lain:

a. Prestasi yang diraih (achievement)

b. Pengakuan orang lain (recognition)

c. Tanggung jawab (responsibility)

d. Peluang untuk maju (advancement)

e. Kepuasan kerja itu sendiri (the work it self)

f. Kemungkinan pengembangan karir (the possibility of growth)

\section{Lingkungan Kerja}

Lingkungan kerja merupakan salah satu faktor penting yang perlu diperhatikan oleh seorang manajer dalam memelihara sumber daya manusianya, yaitu dengan cara menyediakan dan mengupayakan lingkungan kerja yang nyaman, aman dan kondusif karena disitulah seorang pegawai menghabiskan waktu kerjanya setiap hari, maka dengan lingkungan kerja yang nyaman, aman dan kondusif akan meningkatkan semangat kerja yang tinggi.

Pengertian Lingkungan kerja menurut Alex Nitisemito (1996: 183), bahwa "Lingkungan kerja adalah segala sesuatu yang ada di sekitar pekerja dan yang dapat mempengaruhi dirinya dalam menjalankan tugas-tugas yang dibebankan".

Menurut Edy Sutrisno (2009: 118), tentang pengertian lingkungan kerja adalah: Keseluruhan sarana dan prasarana kerja yang ada di sekitar karyawan yang sedang melakukan pekerjaan yang dapat mempengaruhi pelaksanaan pekerjaan meliputi tempat bekerja, fasilitas, kebersihan, pencahayaan, ketenangan, termasuk juga hubungan kerja antara orang-orang yang ada ditempat tersebut.

Sehingga gairah kerja para karyawan akan meningkat.

Sedamayanti (2011:25) menyatakan bahwa lingkungan kerja non fisik adalah semua keadaan yang terjadi yang berkaitan dengan hubungan kerja, baik hubungan dengan atasan maupun hubungan dengan bawahan sesama rekan kerja, ataupun hubungan dengan bawahan.

Adapun 5 indikator lingkungan kerja non fisik yang bisa mempengaruhi perilaku karyawan, yaitu:

a. Struktur kerja

b. Tanggung jawab kerja

c. Perhatian dan dukungan pemimpin

d. Kerja sama antar kelompok

e. Kelancaran komunikasi 


\section{Kinerja}

Menurut Prawirosentono (2008: 64), kinerja adalah sesuatu yang dicapai seseorang atau kelompok dalam organisasi yang sesuai dengan wewenang dan tanggung jawab masing-masing dalam rangka mencapai tujuan perusahaan secara legal, dan tidak melanggar hukum, moral, dan etika.

Menurut Simamora (2004) deskripsi dari kinerja menyangkut tiga komponen penting yaitu:

a. Tujuan. Tujuan ini akan memberikan arah dan mempengaruhi bagaimana seharusnya perilaku kerja yang diharapkan organisasi terhadap setiap personil.

b. Ukuran. Ukuran dibutuhkan untuk mengetahui apakah seorang personil telah mencapai kinerja yang diharapkan, untuk itu kuantitatif dan kualitatif standar kinerja untuk setiap tugas dan jabatan personal memegang peranan penting.

c. Penilaian. Penilaian kinerja reguler yang dikaitkan dengan proses pencapaian tujuan kinerja setiap personil. Tindakan ini akan membuat personil untuk senantiasa berorientasi terhadap tujuan dan berperilaku kerja sesuai dan searah dengan tujuan yang hendak dicapai.

Hasil kerja seseorang akan memberikan umpan balik bagi orang itu sendiri untuk selalu aktif melakukan pekerjaannya secara baik dan diharapkan akan menghasilkan mutu pekerjaan yang baik pula. Pendidikan mempengaruhi kinerja seseorang karena dapat memberikan wawasan yang lebih luas untuk berinisiatif, berinovasi dan selanjutnya berpengaruh terhadap kinerjanya.

Mangkunegara (2009: 68) menyatakan bahwa faktor yang mempengaruhi kinerja karyawan adalah sebagai berikut:

a. Faktor Kemampuan . Secara psikologis, kemampuan (ability) karyawan terdiri dari kemampuan potensi (IQ) dan kemampuan reality (knowledge+ skill).

b. Faktor Motivasi. Motivasi merupakan kondisi yang menggerakkan diri karyawan yang terarah untuk mencapai tujuan organisasi (tujuan kerja).

Berdasarkan pembahasan diatas, dapat disimpulkan kinerja merupakan pelaksanaan kerja, pencapaian kerja, dan hasil kerja yang sesuai dengan wewenang dan tanggung jawab masing-masing dalam rangka mencapai tujuan perusahaan secara legal, dan tidak melanggar hukum, moral, dan etika, yang dapat diukur dalam periode tertentu.

Sastrohadiwiryo (2005:231-236) "kinerja adalah hasil yang dicapai oleh seorang tenaga kerja dalam melaksanakan tugas dan pekerjaan yang diberikan kepadanya". Pada umumnya unsur-unsur yang perlu diadakan penilaian dalam proses penilaian kinerja adalah:
a. Kesetiaan
b. Prestasi kerja
c. Tanggung jawab
d. Ketaatan
e. Kejujuran
f. Kerjasama
g. Prakarsa
h. Kepemimpinan 


\section{KERANGKA PIKIR}

Berdasarkan kajian penelitian terdahulu dan kajian teori dapat digambarkan kerangka pemikiran sebagai berikut:

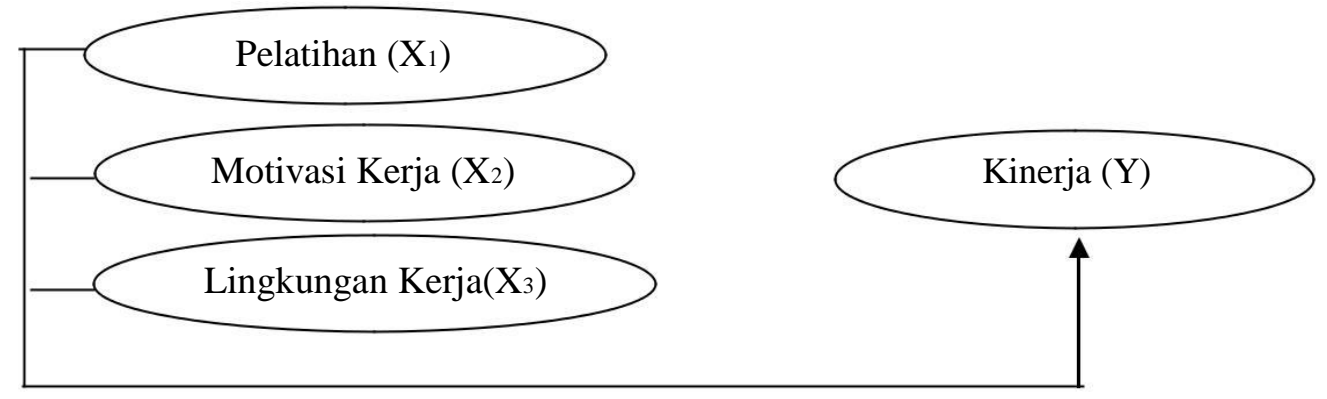

Gambar 1

Kerangka Pemikiran

Keterangan:

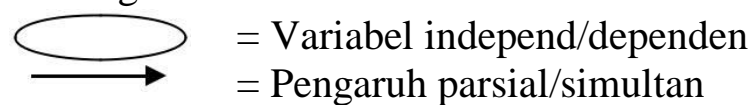

\section{HIPOTESIS}

Dalam kaitannya dengan permasalahan yang telah dikemukakan, maka penulis mengemukakan hipotesis atas masalah tersebut di atas adalah bahwa:

1. Secara bersama-sama variabel pelatihan $\left(X_{1}\right)$, motivasi kerja $\left(X_{2}\right)$, dan lingkungan kerja $\left(\mathrm{X}_{3}\right)$ mempunyai pengaruh terhadap kinerja karyawan (Y) Kementerian Perhubungan di Unit Kerja Direktorat Jenderal Perhubungan Udara Pada Kantor Otoritas Bandar Udara Wilayah VII Balikpapan.

2. Secara sendiri-sendir atau secara parsial variabel pelatihan $\left(\mathrm{X}_{1}\right)$, motivasi kerja $\left(\mathrm{X}_{2}\right)$, dan lingkungan kerja $\left(\mathrm{X}_{3}\right)$ mempunyai pengaruh terhadap kinerja karyawan (Y) Kementerian Perhubungan di Unit Kerja Direktorat Jenderal Perhubungan Udara Pada Kantor Otoritas Bandar Udara Wilayah VII Balikpapan.

3. Variabel Motivasi kerja $\left(\mathrm{X}_{2}\right)$ mempunyai pengaruh dominan terhadap kinerja karyawan (Y) Kementerian Perhubungan di Unit Kerja Direktorat Jenderal Perhubungan Udara Pada Kantor Otoritas Bandar Udara Wilayah VII Balikpapan.

\section{METODE RESEARCH}

\section{Populasi dan Sampel}

Sugiyono (2011:34) Populasi adalah wilayah generalisasi yang terdiri atas obyek/subyek yang mempunyai kualitas dan karakteristik tertentu yang ditetapkan oleh peneliti untuk dipelajari dan kemudian ditarik kesimpulannya. Populasi dalam penelitian pada karyawan Kementerian Perhubungan di Unit Kerja Direktorat Jenderal Perhubungan Udara Pada Kantor Otoritas Bandar Udara Wilayah VII Balikpapan yang berjumlah 45 karyawan. 
Adapun metode pengambilan sampel dalam penelitian ini diambil secara sensus yaitu sebanyak 45 orang karyawan.

\section{Pengujian Instrumen penelitian}

Pengujian Instrumen penelitian adalah pengujian terhadap item kuesioner dilakukan dengan cara:

1. Uji Validitas

Syarat minimum untuk dianggap valid adalah nilai $r$ hitung $>$ dari nilai $r$ tabel. Adapun perhitungan korelasi frogram SPSS formula Pearson product moment dengan hasil dibandingkan dengan Pearson product moment tabel dengan sampel 30 pada $\alpha 5 \%(0,05)$ diketahui nilai Pearson product moment Tabel adalah 0,361 maka apabila: nilai $\mathrm{r}$ hitung > 0,361 dinyatakan Valid dan apabila nilai $r$ hitung $<0,361$ dinyatakan tidak valid.

2. Uji Reliabity

Arikunto (2008:145) dimaksudkan "untuk mengetahui adanya konsistensi alat ukur dalam penggunaannya, atau dengan kata lain alat ukur tersebut mempunyai hasil yang konsisten apabila digunakan berkali-kali pada waktu yang berbeda".dan "Untuk uji reliabilitas digunakan Teknik Alpha Cronbach, yaitu dengan membandingkan nila $r$ Alpha Cronbach dengan $r$ Alpha Cronbach tabel dimana suatu instrumen dapat dikatakan handal (reliabel) bila memiliki koefisien keandalan atau alpha sebesar 0,60 atau lebih" dan jika nila r Alpha Cronbach < 0,60 dinyatakan tidak reliabel.

3. Regresi Linear berganda

Analisis juga dilaksanakan untuk mengkaji hipotesis yang diajukan dalam penelitian dan menganalisis data secara keseluruhan dengan metode statistik menggunakan program komputer statistik SPSS, Perhitungan persamaan regresi berganda (Multiple Regression) menurut J. Supranto dalam buku Ekonometrika (2004:18) Persamaan Regresi linear berganda untuk menganalisis pengaruh Variabel pelatihan $\left(\mathrm{X}_{1}\right)$, moivasi Kerja $\left(\mathrm{X}_{2}\right)$, lingkungan kerja (X3), terhadap variabel Kinerja Karyawan (Y) Kementerian Perhubungan di Unit Kerja Direktorat Jenderal Perhubungan Udara Pada Kantor Otoritas Bandar Udara Wilayah VII Balikpapan:

$$
\mathrm{Y}=\mathrm{b}_{0}+\mathrm{b}_{1} \mathrm{X}_{1}+\mathrm{b}_{2} \mathrm{X}_{2}+\mathrm{b}_{3} \mathrm{X}_{3}+\mathrm{e}_{1}
$$

\section{Pengujian Penyimpangan Klasik}

Model regresi linear berganda akan lebih tepat di gunakan, jika memenuhi asumsi klasik berikut ini:

\section{Multikolinieritas}

Ukuran ini menunjukan setiap variabel bebas manakah yang di jelaskan oleh variabel bebas lainya. Dalam pengertian sederhana setiap variabel bebas menjadi variabel terikatdan diregres terhadap variabel bebas lainya. Bila nilai VIF $>5$ berarti terjadi multikolinieritas, dan sebaliknya bila nilai VIF $<5$ berarti tidak terjadi multikolinieritas. 
2. Heteroskedastisitas

Asumsi klasik mengatakan bahwa model tidak boleh terjadi heteroskedastisitas. Gejalah heteroskedastisitas terjadi sebagai akibat dari adanya ketidak samaan varians residual dari satu pengamatan ke pengamatan yang lain. Jika varians residualnya berbeda maka terjadi heteroskedastisitas. Model regresi yang baik adalah tidak terjadi heteroskedastisitas.

\section{Autokorelasi}

Untuk mendeteksi adanya atau tidaknya autokorelasi ini dapat di lakukan dengan mengunakan uji Durbin Waston (DW). Dengan demikian oleh Uji Durbin Watson (Dw test) berikut adalah dasar analisis untuk mengambil keputusan terjadi tidaknya autokorelasi: dalam Algifari (2010:102) bila angka DW kurang dari 1,21 telah terjadi autokorelasi. Bila DW 1,21 -1,65 di katakan tidak ada kesimpulan. Bila DW 1,65 sampai dengan 2,35 dinyatakan tidak terjadi autokorelasi. Sedangkan 2,35 sampai dengan 2,79 dinyatakan tidak ada kesimpulan dan lebih 2,79 ada autokorelasi.

\section{HASIL DAN PEMBAHASAN}

\section{Hasil Uji Validitas}

Tabel 1

Hasil Uji Validitas

\begin{tabular}{|c|c|c|c|c|}
\hline Variabel & Item & $\begin{array}{c}\text { Pearson } \\
\text { correlations }\end{array}$ & $\begin{array}{c}\mathrm{r} \text { tabel } \\
\mathrm{n}=30\end{array}$ & keterangan \\
\hline \multirow{8}{*}{ Kinerja (Y) } & $\begin{array}{l}\text { Y1.1 } \\
\end{array}$ & 0,688 & 0.361 & Valid \\
\hline & $\mathrm{Y} 1.2$ & 0,658 & 0.361 & Valid \\
\hline & Y1.3 & 0,675 & 0.361 & Valid \\
\hline & Y1.4 & 0,575 & 0.361 & Valid \\
\hline & Y1.5 & 0,755 & 0.361 & Valid \\
\hline & Y1.6 & 0,789 & 0.361 & Valid \\
\hline & Y1.7 & 0,803 & 0.361 & Valid \\
\hline & Y1.8 & 0,430 & 0.361 & Valid \\
\hline \multirow{5}{*}{ Pelatihan $\left(\mathrm{X}_{1}\right)$} & $\mathrm{X}_{1.1}$ & 0,423 & 0.361 & Valid \\
\hline & $X_{1.2}$ & 0,594 & 0.361 & Valid \\
\hline & $X_{1.3}$ & 0,586 & 0.361 & Valid \\
\hline & $X_{1.4}$ & 0,654 & 0.361 & Valid \\
\hline & $X_{1.5}$ & 0,586 & 0.361 & Valid \\
\hline \multirow{6}{*}{ Motivasi kerja (X2) } & $\mathrm{X}_{2.1}$ & 0,721 & 0.361 & Valid \\
\hline & $\mathrm{X}_{2.2}$ & 0,692 & 0.361 & Valid \\
\hline & $\mathrm{X}_{2.3}$ & 0,568 & 0.361 & Valid \\
\hline & $\mathrm{X}_{2.4}$ & 0,379 & 0.361 & Valid \\
\hline & $X_{2.5}$ & 0,785 & 0.361 & Valid \\
\hline & $\mathrm{X}_{2.6}$ & 0,663 & 0.361 & Valid \\
\hline \multirow{5}{*}{ Ligkungan kerja (X3) } & $\mathrm{X}_{3.1}$ & 0,784 & 0.361 & Valid \\
\hline & $\mathrm{X}_{3.2}$ & 0,729 & 0.361 & Valid \\
\hline & $\mathrm{X}_{3.3}$ & 0,854 & 0.361 & Valid \\
\hline & $\mathrm{X}_{3.4}$ & 0,696 & 0.361 & Valid \\
\hline & $\mathrm{X}_{3.5}$ & 0,778 & 0.361 & Valid \\
\hline
\end{tabular}

Sumber: Hasil analisis dengan menggunakan tabel dan SPSS 20 
Pada tabel 1 hasil proses data diketahui besarnya koefisien korelasi dari setiap pertanyaan untuk masing-masing Variabel Pelatihan $\left(\mathrm{X}_{1}\right)$, Motivasi kerja $\left(\mathrm{X}_{2}\right)$, dan Lingkungan kerja ( $\left.\mathrm{X}_{3}\right)$ mempengaruhi terhadap Kinerja Karyawan (Y) Kementerian Perhubungan di Unit Kerja Direktorat Jenderal Perhubungan Udara Pada Kantor Otoritas Bandar Udara Wilayah VII Balikpapan dengan nilai Pearson Correlation positif dan karena $\mathrm{r}$ hitung $>$ rtabel yaitu 0,361 .

\section{Hasil Uji Reabilitas}

Tabel 2

Hasil Pengujian Reliabilitas

\begin{tabular}{|l|c|c|c|}
\hline \multicolumn{1}{|c|}{ Variabel } & $\begin{array}{c}\text { Nilai r hitung } \\
\text { Alpha } \\
\text { Crounbach }\end{array}$ & $\begin{array}{c}\text { Nilai r tabel } \\
\text { Alpha Crounbach }\end{array}$ & Keterangan \\
\hline Kinerja (Y) & 0,771 & 0,60 & Reliable \\
\hline Pelatihan(X) $\left(\mathrm{X}_{1}\right)$ & 0,718 & 0,60 & Reliable \\
\hline Motivasi kerja (X2) & 0,754 & 0,60 & Reliable \\
\hline Lingkungan kerja (X3) & 0,799 & 0,60 & reliable \\
\hline
\end{tabular}

Sumber: Hasil analisis dengan menggunakan tabel dan SPSS 20

Semua pertanyaan untuk masing-masing variabel dalam penelitian ini dapat dinyatakan reliabel karena memiliki nilai Cronbach's Alpha sebesar > 0,60 maka dapat disimpulkan bahwa pertanyaan mengenai Variabel Pelatihan $\left(\mathrm{X}_{1}\right)$, Motivasi kerja $\left(\mathrm{X}_{2}\right)$, dan Lingkungan kerja $\left(\mathrm{X}_{3}\right)$ mempengaruhi terhadap Kinerja Karyawan (Y) Kementerian Perhubungan di Unit Kerja Direktorat Jenderal Perhubungan Udara Pada Kantor Otoritas Bandar Udara Wilayah VII Balikpapan merupakan pertanyaan yang reliable, dan dapat diartikan bahwa secara menyeluruh kuesioner yang digunakan dinyatakan reliabel atau andal.

\section{Analisis Data}

Berdasarkan Hasil analisis dengan menggunakan SPSS versi 20 diperoleh Analisis Regresi Linear Berganda sebagai berikut:

Tabel 3

Hasil secara Simultan

\begin{tabular}{|c|c|c|c|c|c|}
\hline $\begin{array}{c}\text { Koefisien } \\
\text { Korelasi (R) }\end{array}$ & $\begin{array}{c}\text { Koefisien } \\
\text { Determinasi } \\
\text { (R Square) }\end{array}$ & F hitung & F tabel & Nilai Sig & Keterangan \\
\hline 0,927 & 0,859 & 82,937 & 2,83 & 0,000 & Signifikan \\
\hline
\end{tabular}

Sumber : SPSS 
Tabel 4

Hasil Koefisien Regresi, Korelasi dan Uji t

\begin{tabular}{|l|c|c|c|c|c|c|}
\hline \multicolumn{1}{|c|}{ Variabel } & $\begin{array}{c}\text { Koefisien } \\
\text { Regresi } \\
(\mathrm{b})\end{array}$ & $\begin{array}{c}\text { Koefisien } \\
\text { Korelasi } \\
\text { Parsial } \\
(\mathrm{r})\end{array}$ & $\begin{array}{c}\mathrm{t} \\
\text { hitung }\end{array}$ & $\mathrm{t}$ tabel & $\mathrm{Sig}$ & Keterangan \\
\hline KinerjaKaryawan (Y) & 0,534 & & & & & \\
Konstanta & 0,292 & 0,468 & 3.387 & 2,021 & 0,002 & Signifikan \\
Pelatihan (X) & 0,348 & 0,508 & 3,773 & 2,021 & 0,001 & Signifikan \\
Motivasi kerja $\left(\mathrm{X}_{2}\right)$ & 0,268 & 0,490 & 3,596 & 2,021 & 0,001 & Signifikan \\
Lingkungan kerja $\left(\mathrm{X}_{3}\right)$ & 0,201 \\
\hline
\end{tabular}

Sumber : Data Primer yang diolah menggunakan SPSS Versi 20

\section{Pembahasan dari hasil Analisis}

\section{Regresi Linear Berganda.}

Persamaan regresi linier berganda untuk hasil penelitian Variabel Pelatihan $\left(\mathrm{X}_{1}\right)$, Motivasi kerja $\left(\mathrm{X}_{2}\right)$, dan Lingkungan kerja mempengaruhi terhadap Kinerja Karyawan (Y) Kementerian Perhubungan di Unit Kerja Direktorat Jenderal Perhubungan Udara Pada Kantor Otoritas Bandar Udara Wilayah VII Balikpapan yaitu:

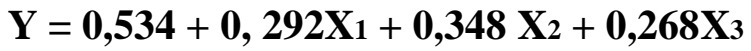

Nilai koefisien konstanta sebesar bo $=0,534$ menunjukan pada saat variabel-variabel Variabel Pelatihan $\left(\mathrm{X}_{1}\right)$, Motivasi kerja $\left(\mathrm{X}_{2}\right)$, dan Lingkungan kerja (X3) mempengaruhi terhadap Kinerja Karyawan (Y) Kementerian Perhubungan di Unit Kerja Direktorat Jenderal Perhubungan Udara Pada Kantor Otoritas Bandar Udara Wilayah VII Balikpapan nilainya menunjukkan nilai konstan atau nol maka variabel Kinerja Karyawan (Y) Kementerian Perhubungan di Unit Kerja Direktorat Jenderal Perhubungan Udara Pada Kantor Otoritas Bandar Udara Wilayah VII Balikpapan sebesar bo $=0,534$.

Hubungan antara variabel pelatihan $\left(\mathrm{X}_{1}\right)$ terhadap variabel kinerja Karyawan (Y) Kementerian Perhubungan di Unit Kerja Direktorat Jenderal Perhubungan Udara Pada Kantor Otoritas Bandar Udara Wilayah VII

Balikpapan dengan nilai koefisien regresi b1 sebesar 0,292 menunjukkan setiap kenaikan variabel Pelatihan $\left(\mathrm{X}_{1}\right)$ sebesar satu satuan akan

mempengaruhi terhadap peningkatan variabel Kinerja Karyawan (Y) Kementerian Perhubungan di Unit Kerja Direktorat Jenderal Perhubungan Udara Pada Kantor Otoritas Bandar Udara Wilayah VII Balikpapan sebesar 0,292 dengan asumsi variabel Variabel Motivasi kerja $\left(\mathrm{X}_{2}\right)$ dan Lingkungan kerja $\left(\mathrm{X}_{3}\right)$ nilainya konstan.

Hubungan antara variabel motivasi kerja $\left(\mathrm{X}_{2}\right)$ terhadap variabel kinerja Karyawan (Y) Kementerian Perhubungan di Unit Kerja Direktorat Jenderal Perhubungan Udara Pada Kantor Otoritas Bandar Udara Wilayah VII Balikpapan dengan Nilai koefisien regresi b2 sebesar 0,348 menunjukkan setiap kenaikan variabel Motivasi kerja $\left(\mathrm{X}_{2}\right)$ sebesar satu satuan akan mempengaruhi terhadap peningkatan variabel Kinerja Karyawan (Y) Kementerian Perhubungan di Unit Kerja Direktorat Jenderal Perhubungan Udara Pada Kantor Otoritas Bandar Udara Wilayah VII Balikpapan sebesar 
0,348 dengan asumsi variabel Variabel Pelatihan ( $\left.\mathrm{X}_{1}\right)$ dan Lingkungan kerja $\left(\mathrm{X}_{3}\right)$ nilainya konstan.

Hubungan antara variabel lingkungan kerja $\left(\mathrm{X}_{2}\right)$ terhadap variabel kinerja Karyawan (Y) Kementerian Perhubungan di Unit Kerja Direktorat Jenderal Perhubungan Udara Pada Kantor Otoritas Bandar Udara Wilayah VII Balikpapan dengan Nilai koefisien regresi $b_{3}$ sebesar 0,268 menunjukkan setiap kenaikan variabel Lingkungan kerja (X3) sebesar satu satuan akan mempengaruhi terhadap peningkatan variabel Kinerja Karyawan (Y) Kementerian Perhubungan di Unit Kerja Direktorat Jenderal Perhubungan Udara Pada Kantor Otoritas Bandar Udara Wilayah VII Balikpapan sebesar 0,268 dengan asumsi variabel Pelatihan $\left(\mathrm{X}_{1}\right)$, Motivasi kerja $\left(\mathrm{X}_{2}\right)$ nilainya konstan.

\section{Pengujian Asumsi Klasik}

\section{a. Uji Multikolinieritas}

Tabel 5

Hasil Uji Multikolinearitas

\begin{tabular}{|l|c|c|c|}
\hline \multicolumn{1}{|c|}{ Variabel } & $\begin{array}{c}\text { Nilai } \\
\text { VIF }\end{array}$ & $\begin{array}{c}\text { Nilai } \\
\text { Kritis }\end{array}$ & Keterangan \\
\hline Pelatihan $\left(\mathrm{X}_{1}\right)$ & 2,737 & 5 & Tidak terjadi Multikolinearity \\
Motivasi kerja $\left(\mathrm{X}_{2}\right)$ & 2,662 & 5 & Tidak terjadi Multikolinearity \\
Lingkungan kerja $\left(\mathrm{X}_{3}\right)$ & 2,471 & 5 & Tidak terjadi Multikolinearity \\
\hline
\end{tabular}

Sumber data : analisis menggunakan SPSS Versi 20

Berdasarkan tabel 5 tersebut dapat diketahui bahwa variabel bebas yaitu Variabel Pelatihan $\left(\mathrm{X}_{1}\right) \mathrm{VIF}=2,737$, Motivasi kerja $\left(\mathrm{X}_{2}\right)$ VIF $=$ 2,662 dan Lingkungan kerja $\left(\mathrm{X}_{3}\right) \mathrm{VIF}=2,471$ menunjukkan tidak terjadi Multikolinearity karena nilai VIF (Variance Inflation Factor) semua lebih kecil dari 5 pada matrik korelasi menunjukkan lebih besar dari nilai kritisnya untuk $\alpha=0,05$.

\section{b. Uji Heteroskedastisitas}

Tabel 6

\section{Hasil Uji Heteroskedastisitas}

\begin{tabular}{|l|c|c|c|}
\hline \multicolumn{1}{|c|}{ Variabel } & $\begin{array}{c}\text { Koefisien } \\
\text { Beta }\end{array}$ & $\begin{array}{c}\text { Nilai } \\
\text { Sig }\end{array}$ & keterangan \\
\hline Pelatihan $\left(\mathrm{X}_{1}\right)$ & 0,329 & 0,05 & Tidak terjadi Heteroskedastis \\
Motivasi kerja $\left(\mathrm{X}_{2}\right)$ & 0,362 & 0,05 & Tidak terjadi Heteroskedastis \\
Lingkungan kerja $\left(\mathrm{X}_{3}\right)$ & 0,332 & 0,05 & Tidak terjadi Heteroskedastis \\
\hline
\end{tabular}

Sumber Data : Pengolahan dengan SPSS versi 20.

Hasil pada tabel 6 tersebut Pelatihan $\left(\mathrm{X}_{1}\right)$ nilai koefisien beta $=$ 0,329, Motivasi kerja $\left(\mathrm{X}_{2}\right)$ nilai koefisien beta $=0,362$,Lingkungan kerja $\left(\mathrm{X}_{3}\right)$ nilai koefisien beta $=0,332$ nilai koefisien Beta menunjukkan Tidak terjadi Heteroskedastis > 0,05 Diketahui bahwa ternyata Nilai $\beta$ ( Beta) variabel bebas lebih besar dari nilai kritis pada taraf $\alpha=0,05$ sehingga dapat dikatakan tidak terjadi heteroskedastisitas. 


\section{c. Uji Autokorelasi}

Tabel 6

Tabel Durbin Watson

\begin{tabular}{|c|c|c|}
\hline Interval & Hasil analisis & Keterangan \\
\hline DW kurang dari 1,21 & - & Terjadi Autokorelasi \\
\hline DW $1,21-1,65$ & - & Tidak ada kesimpulan \\
\hline $1,65-2,35$ & 2,287 & Tidak terjadi Autokorelasi \\
\hline DW $2,35-2,79$ & - & Tidak ada kesimpulan \\
\hline Lebih dari 2,79 & - & Terjadi Autokorelasi \\
\hline
\end{tabular}

Berdasarkan hasil analisis pada tabel 6 diperoleh nilai Durbin Watson hitung sebesar 2,287 nilai ini berada pada nilai interval Dubin Watson Tabel yaitu antara DW 1,65 sampai dengan 2,35 dixcnyatakan tidak terjadi autokorelasi. Dengan melihat hasil pengujian terhadap pelanggaran asumsi klasik dimana tidak terjadi Multikolinearity, tidak terjadi heteroskedastis dan tidak terjadi Autokasi maka analisis regresi linear berganda dapat dipergunakan sebagai model alat analisis bagi pengujian hipotesis penelitian.

\section{PEMBAHASAN}

Hasil penelitian menunjukkan bahwa dapat diketahui pengaruh variabel independen secara simultan yaitu variabel pelatihan $\left(\mathrm{X}_{1}\right)$, motivasi $\left(\mathrm{X}_{2}\right)$, dan lingkungan kerja ( $\left.\mathrm{X}_{3}\right)$ terhadap variabel dependen yaitu kinerja (Y) menunjukkan pengaruh yang positif sebesar $\mathrm{R}=0,927(92,7 \%)$ dan kontribusi secara simultan $\mathrm{R}$ Square (koefisien determinan simultan) sebesar 0,859 (85,9\%). Antara variabel pelatihan $\left(\mathrm{X}_{1}\right)$, motivasi $\left(\mathrm{X}_{2}\right)$, dan lingkungan kerja $\left(\mathrm{X}_{3}\right)$ mempunyai kontribusi terhadap variabel kinerja karyawan (Y) di Unit Kerja Direktorat Jenderal Perhubungan Udara Pada Kantor Otoritas Bandar Udara Wilayah VII Balikpapan sebesar $92,7 \%$ dan sisanya 7,3\% dipengaruhi variabel lainnya diluar model yang diteliti. Berdasarkan hasil analisis pada level $95 \% \mathrm{a}=0,05$ dengan degree of freedom (df) n-k-1 = 52 dan k-1 = 4-1, diperoleh nilai Fhitung sebesar 82,937 dan Ftabel sebesar 2,83 artinya Fhitung $>$ Ftabel yaitu 82,937 $>2,83$ pada sig 0,000 0,05. Dari hasil analisis dan pembahasan tersebut, maka variabel pelatihan ( $\left.\mathrm{X}_{1}\right)$, motivasi $\left(\mathrm{X}_{2}\right)$, dan lingkungan kerja $\left(\mathrm{X}_{3}\right)$ secara bersama-sama mempunyai pengaruh terhadap kinerja karyawan di Unit Kerja Direktorat Jenderal Perhubungan Udara Pada Kantor Otoritas Bandar Udara Wilayah VII Balikpapan. Penelitian yang mendukung bahwa terdapat pengaruh secara bersama-sama variabel pelatihan, motivasi dan lingkungan kerja terhadap kinerja karyawan adalah penelitian Max Saleleng dan Supandi Soegoto.

Berdasarkan hipotesis penelitian ini pelatihan memiliki pengaruh positif dan signifikan terhadap kinerja karyawan di Unit Kerja Direktorat Jenderal Perhubungan Udara Pada Kantor Otoritas Bandar Udara Wilayah VII Balikpapan, dapat dibuktikan dengan melihat nilai thitung 3,387>2,021 dengan nilai signifikan sebesar $0,002<0,05$ nilai $\mathrm{r}$ parsial sebesar 0,468 atau $46,8 \%$. Dengan demikian pelatihan harus terus dilakukan untuk meningkatkan kinerja karyawan. Penelitian yang mendukung bahwa terdapat pengaruh variabel pelatihan terhadap 
kinerja karyawan yaitu penelitian yang dilakukan oleh Sri Kurniawati Padma Dewi Dan Titi Laras.

Berdasarkan hipotesis penelitian ini juga motivasi memiliki pengaruh positif dan signifikan terhadap kinerja karyawan di Unit Kerja Direktorat Jenderal Perhubungan Udara Pada Kantor Otoritas Bandar Udara Wilayah VII Balikpapan, dapat dibuktikan dengan melihat nilai thitung 3,773>2,021 dengan nilai signifikan sebesar 0,001 $<0,05$ nilai r parsial sebesar 0,508 atau 50,8\%. Dengan demikian motivasu harus terus diperhatikan dan dibangun untuk meningkatkan kinerja karyawan. Penelitian yang mendukung bahwa terdapat pengaruh variabel motivasi terhadap kinerja karyawan yaitu penelitian yang dilakukan oleh Max Saleleng, dimana variable motivasi mempunyai pengaruh yang dominan terhadap kinerja karyawan.

Berdasarkan hipotesis penelitian ini juga lingkungan kerja memiliki pengaruh positif dan signifikan terhadap kinerja karyawan di Unit Kerja Direktorat Jenderal Perhubungan Udara Pada Kantor Otoritas Bandar Udara Wilayah VII Balikpapan, dapat dibuktikan dengan melihat nilai thitung 3,596 > 2,021 dengan nilai signifikan sebesar $0,001<0,05$ nilai $r$ parsial sebesar 0,490 atau 49,0\%. Dengan demikian lingkungan kerja harus terus diperhatikan dan dibangun untuk meningkatkan kinerja karyawan. Penelitian yang mendukung bahwa terdapat pengaruh variabel lingkungan kerja terhadap kinerja karyawan yaitu penelitian yang dilakukan oleh Maya Agustin Mandey dan Victor P.K Lengkong.

\section{KESIMPULAN DAN SARAN}

\section{Kesimpulan}

Berdasarkan analisis dan pembahasan maka dapat dikemukakan suatu kesimpulan dari penelitian adalah adalah :

1. Bahwa Variabel Pelatihan $\left(X_{1}\right)$, Motivasi kerja $\left(X_{2}\right)$, dan Lingkungan kerja (X3) secara bersama-sama mempunyai pengaruh terhadap Kinerja Karyawan (Y) Kementerian Perhubungan di Unit Kerja Direktorat Jenderal Perhubungan Udara Pada Kantor Otoritas Bandar Udara Wilayah VII Balikpapan telah terbukti kebenarannya dan diterima dan terbukti dengan pengujian secara simultan yaitu dengan uji $\mathrm{F}$ dan hasil koefisien Determinasi ( $\mathrm{R}$ square) yang menunjukkan pengaruh yang besar hal ini juga sejalan dengan hasil penelitian terdahulu yaitu penelitian Max Saleleng dan Supandi Soegoto dan penelitian Asri Warnanti.

2. Bahwa variabel Motivasi kerja $\left(\mathrm{X}_{2}\right)$ yang merupakan variabel dominan mempengaruhi variabel Kinerja Karyawan (Y) Kementerian Perhubungan di Unit Kerja Direktorat Jenderal Perhubungan Udara Pada Kantor Otoritas Bandar Udara Wilayah VII Balikpapan sejalan dengan hasil penelitian Max Saleleng dan Supandi Soegoto.

3. Pelatihan $\left(X_{1}\right)$, Lingkungan kerja $\left(X_{3}\right)$ juga mempunyai pengaruh yang signifikan terhadap Kinerja Karyawan (Y) Kementerian Perhubungan di Unit Kerja Direktorat Jenderal Perhubungan Udara Pada Kantor Otoritas Bandar Udara Wilayah VII Balikpapan. 


\section{Saran-saran}

Sebagai saran dari peneliti adalah sesuai dengan hasil penelitian ini yang diharapkan dapat bermanfaat baik bagi Kinerja Karyawan (Y) Pada Kementerian Perhubungan di Unit Kerja Direktorat Jenderal Perhubungan Udara Pada Kantor Otoritas Bandar Udara Wilayah VII Balikpapan.

1. Mengingat bahwa variabel Motivasi kerja $\left(\mathrm{X}_{2}\right)$ mempunyai pengaruh yang dominan dan signifikan terhadap Kinerja Karyawan (Y) Kementerian Perhubungan di Unit Kerja Direktorat Jenderal Perhubungan Udara Pada Kantor Otoritas Bandar Udara Wilayah VII Balikpapan maka perusahaan dan pimpinan hendaknya dapat memperhatikan kebutuhan karyawan baik secara finance maupun dalam pengambangan karier bagi karyawan untuk meningkatnya kinerja karyawan sesuai harapan perusahaan.

2. Oleh karena variabel Lingkungan kerja ( $\left.\mathrm{X}_{3}\right)$ yang merupakan variabel mempengaruhi variabel Kinerja Karyawan (Y) Kementerian Perhubungan di Unit Kerja Direktorat Jenderal Perhubungan Udara Pada Kantor Otoritas Bandar Udara Wilayah VII Balikpapan maka hendaknya perusahaan dan pimpinan dapat mempertahankan memperhatikan lingkungan kerja yang nyaman, kondisif dan layak bagi karyawan baik yang berdasarkan aturan ketenagakerjaaan dan perburuhan.

3. Mengingat bahwa Pelatihan $\left(\mathrm{X}_{1}\right)$ merupakan variabel mempunyai pengaruh terhadap Kinerja Karyawan (Y) Kementerian Perhubungan di Unit Kerja Direktorat Jenderal Perhubungan Udara Pada Kantor Otoritas Bandar Udara Wilayah VII Balikpapan maka hendaknya organisasi mapupun pimpinan memberi kesempatan bagi karyawan mengikuiti pelatihan agar karyawan dapat meningkatkan kemampuannya sehingga akan lebih menguntungkan perusahaan dengan meningkatnya Kinerja karyawan yang diharapkan.

\section{DAFTAR PUSTAKA}

Aan Hardiyana, Farina Helwiyan, Pengaruh Kepemimpinan, Motivaasi dan Lingkungan Kerja Terhadap Kinerja Pegawai Badan Kepegawaian Pendidikan dan Pelatihan Kabupate Bandung, Jurnal Ekonomi, Bisnis \& Entrepreneurship Vol. 5, No. 2, Oktober 2011, 86-96 ISSN 2443-0633.

Anwar Prabu Mangkunegara. 2005. Evaluasi Kinerja. Bandung : Refika Aditama

Arikunto, Suharsimi. 2006. Prosedur Penelitian Suatu Pendekatan Praktek. Jakarta: Rineka Cipta

Asri Warnanti, Pengaruh Pelatihan, Motivasi dan Lingkungan Kerja Terhadap Prestasi Kerja Karyawan Pada PT. Bank Central Asia Tbk Cabang KCU Thamrin Jakarta Pusat, Jurnal Serambi Hukum Vol. 08 No. 02 Agustus 2014 - Januari 2015 ISSN: 1693-0819.

As’ad, Mohammad. 2001. Psikologi Industri. Liberti. Yogyakarta.

Gomes, Faustino Cardoso, Dr. 2003. MSDM. Yogyakarta: Andi 
Handoko TH,. 2001. Manajemen Personalia dan Sumber Daya Manusia. Edisi 2. Yogyakarta: BPFE

Husein Umar. 2005. Evaluasi Kinerja Perusahaan. Jakarta : Gramedia Pustaka Utama

Sastrohadiwiryo, Siswanto, Manajemen Tenaga Kerja Indonesia Pendekatan Administratif dan Operasional, Jakarta: Bumi Aksara, 2005.

Sedarmayanti. (2009). Sumber Daya Manusia dan Produktivitas Kerja, cetakan ketiga. Bandung : Mandar Maju.

Siagian, Sondang. (2008). Manajemen Sumber Daya Manusia, cetakan kelima belas Jakarta : Bumi Aksara.

Simamora, Henry. 2004. Manajemen Sumber Daya Manusia. Yogyakarta: STIE YKPN. Sorong Selatan, Jurnal EMBA Vol.3 No.3 Sept. 2015, Hal.695708 ISSN 2303-11.

Maya Agustin Mandey dan Victor P.K Lengkong, Pengaruh Kompensasi, Gaya Kepemimpinan, dan Lingkungan Kerja Terhadap Kinerja Pegawai (Studi pada Fakultas Ekonomi dan Bisnis Unsrat) Jurnal EMBA Vol.3 No.3 Sept. 2015, Hal.1383-1394 ISSN 2303-11.

Sri Kurniawati Padma Dewi Dan Titi Laras Pengaruh Pelatihan, Motivaso Kerja, dan Lingkungan Kerja Terhadap Kinerja Karyawan Koperasi Mahasiswa (KOPMA) di Kabupten Sleman, efektif Jurnal Bisnis dan Ekonomi Juni 2014 ol. 5, No 1, Juni 2014, 48 - 72

Sutrisno, Edy. 2009. Manajemen Sumber Daya Manusia. Ed. 1 Jakarta: Kencana Prenada Media Group.

Sugiyono. 2011. Metodelogi Penelitian Administrasi dilengkapi dengan R\&D. Bandung: Alfabeta.

Mangkunegara, Anwar P.2008. Manajemen Sumber Daya Manusia Perusahaan Cetakan Ke-8. Bandung : Rosdakarya

Mathis, Robert L. dan John H. Jackson. 2009. Manajemen Sumber Daya Manusia.Jilid 1. Jakarta : Salemba Empat.

Max Saleleng dan Supandi Soegoto, Pengaruh Lingkungan Kerja, Motivasi, Pelatihan dan Kompensasi Terhadap Kinerja Pegawai Pada Dinas Pertanian Kabupaten 
Jurnal GeoEkonomi ISSN-Elektronik (e): 2503-4790 | ISSN-Print (p): 2086-1117 http://jurnal.fem.uniba-bpn.ac.id/index.php/geoekonomi 